\title{
Expression of Messenger RNA of Oncoproteins E6 and E7 of Human Papilomavirus in Women with Negative Oncotic Cytologies, Epithelial Squamous Atypias of Undefined Significance and Low-Grade Intraepithelial Lesions
}

\author{
Daiene Carvalho Casagrande, Julisa Chamorro Lascasas Ribalta, \\ Katia de Araujo Prado Ferreira Leite, Manoel Schimidt, Neila Maria de Góis Speck* \\ Department of Gynecology, Escola Paulista de Medicina (UNIFESP), São Paulo, Brazil

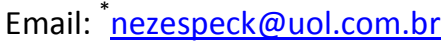

Received 4 December 2014; revised 27 December 2014; accepted 3 January 2015

Academic Editor: Yasam Kemal Akpak, Ankara Mevki Military Hospital, Turkey

Copyright (C) 2015 by authors and Scientific Research Publishing Inc.

This work is licensed under the Creative Commons Attribution International License (CC BY).

http://creativecommons.org/licenses/by/4.0/

(c) (i) 0 pen Access

\begin{abstract}
Objectives: To verify the prevalence of E6/E7 RNAm expression of HPV in patients with negative cervicovaginal cytology, ASC-US and LSIL; to correlate with negative anatomopathological exams and/or squamous intraepithelial neoplasy grade I (SIN 1) of the lower genital tract (LGT); to relate the RNAm expression with viral infection types; to assess the genotyping in single infections. Methods: Findings from 825 women submitted to E6/E7 RNAm survey and 422 women submitted to LGT biopsies were analyzed. Results: A larger percentage of E6/E7 in ASC-US and LSIL cytologies occurred. Negative results of RNAm expression were in accordance with negative cytologies and negative anatomopathological exam. In positive cases, the infection by a single HPV type was most prevalent, with the type 16 being the most common. Conclusions: the expression of mRNA was most prevalent in ASC-US and LSIL cytologies, comparing with the negative ones. The findings of SIN 1 biopsies were related to the positive expression of mRNA and negative cytologies; the negative expression was in agreement with negative anatomopathological exam. The infection by a HPV type was more frequent in cases of positive expression, the HPV type 16 being most frequently found. Patients with low grade intraepithelial lesion cytologies had a higher percentage of
\end{abstract}

\footnotetext{
${ }^{*}$ Corresponding author.

How to cite this paper: Casagrande, D.C., et al. (2015) Expression of Messenger RNA of Oncoproteins E6 and E7 of Human Papilomavirus in Women with Negative Oncotic Cytologies, Epithelial Squamous Atypias of Undefined Significance and Low-Grade Intraepithelial Lesions. Open Journal of Obstetrics and Gynecology, 5, 36-43.

http://dx.doi.org/10.4236/ojog.2015.51006
} 


\section{multiple infections.}

\section{Keywords}

\section{E6/E7 RNAm, Human Papillomavirus, Negative Cytology, ASC-US Cytology, LSIL Cytology}

\section{Introduction}

Cervical cancer ranks second within the most common types of neoplasia in women worldwide, and is the third cause of mortality by cancer in women, ranking second only to breast and colon cancers. In developing countries, it is one of the most frequent types of carcinomas in female sex and might represent over 25\% of all cancers [1] [2].

It is believed that the Human Papillomavirus (HPV) is the causal agent for the development of premalignant and malignant lesions in the cervix, being acknowledged by researchers and epidemiologists as the agent of one of the most common sexually transmitted diseases, both in men or women. This linking was first demonstrated by Harold zur Hausen, in early 1980, which was the reason for him to win the Nobel prize of Medicine in 2009 [3].

It is known that most of the infections by this virus occur in teenagers and young adults below 30 years, clarifying from 1 to 2 years and having no progression to cervix cancer. Nearly a half of women in reproductive age and nearly $80 \%$ of adults are liable to be infected by HPV along their lives [4] [5]. Some co-factors might modify this risk for evolution, including tabagism, multiple sex partners, multiparity, early sexual initiation, use of oral contraceptives for five years or more, co-infection by other infectious agents, such as the human immunodeficiency virus (HIV), Chlamydia trachomatis and herpes simplex virus type 2 (HSV-2) and immunosuppression acquired in organ transplantations [6] [7].

A crucial aspect concerning the understanding of this cancer was the elucidation of the natural history of HPV-caused infections, concluding that the persistence of high oncogenic risk genotypes is the main factor of risk for the development of high grade cervix intraepithelial neoplasias and cervix cancer, in addition to causing other types of cancers. Other determinants for progression are the viral load per cell unit and the integration of viral DNA to the cell one [8] [9].

The high-risk HPV infection is a necessary but not sufficient condition for the invasive disease to progress. For the cervical cancer to occur, it is necessary for an infection to persist for an extended time, a continuous expression of E6 and E7 viral oncogenes, viral integration, mutations in cell genes and the chromosome rearrangement induced by genomic instability [10].

Investments have been made in the search of tumoral markers, so as to better discriminate the potential for regression or not of the infection, including genomic and proteomic analysis, so as to trace the genes and profile and the proteins liable to be used for the differential classification of lesions.

Tests detecting the presence of Messenger RNA that codifies the viral oncoproteins E6 and E7, necessary for the malignant transformation, are available. The detection of such oncogenes allows a better distinction between a temporary HPV infection and the active infection with a chance to progress to cervix cancer [11].

The E6/E7 RNAm transcriptions indicate the expression of those oncogenes initiating the cervix carcinogenesis process, i.e., the quantification of E6 and E7 RNAm might translate the transforming capacity of the relevant HPV, implies an immortalized proliferation and mutation of host squamous epithelial cells. The overexpression of said oncogenes is a transition market from productive to abortive infection, which eventually promotes the cell transformation [12] [13].

This method has shown a better positive predictive value and prognostic value for risk stratification and the possibility of indicating high grade intraepithelial lesions and invasive cancer [14] [15].

\section{Objective}

To assess the expression of high risk E6/E7 oncoproteins of mRNA in women submitted to the cervicovaginal cytopathological exam with results within the limits of normality, atypias of squamous cells of undetermined 
significance (ASC-US) and low grade intraepithelial lesion (LSIL), identifying the prevalence for each cytological finding; to correlate with negative hystopathological finding or low grade neoplasia (SIN), as well as the types of viral infection in respect to the number of HPV, when the expression is positive.

\section{Patients and Methods}

The retrospective observational study was conducted at Laboratório Salomão Zoppi Diagnósticos, through the analysis of medical records of 825 women served from 2009 to 2010, for collect on of the mRNA exam for oncoproteins E6/E7 and cervicovaginal oncotic cytology. Said Laboratory is deemed a reference for the diagnosis of HPV-induced lesions, and the patients sent for said exam presented a history of current or former infection by HPV, with the real clinical diagnosis of the case being unknown.

The inclusion criteria comprised: women with cytological findings within the limits of normality (negative), atypias of squamous cells with undetermined significance (ASC-US) and low grade intraepithelial lesions (LSIL). Women with cytological and/or histological abnormalities beyond low grade lesions and/or intraepithelial neoplasia grade I (SIN I) were not included in the study.

All patients signed the Free Consent Form, standard for Said laboratory. The physician in charge of the Ethics Committee of the institution approved the use of the filed material, through a letter of consent.

The patients were submitted to the following biomolecular tests: mRNA research for oncoproteins E6/E7, using the NucliSENS EasyQ ${ }^{\circledR}$ HPV (BioMerieux) technology and the HPV-DNA test, with the real-time polymerase chain reaction-PCR.

\section{Results}

825 exams of women submitted to mRNA for E6/E7 of high oncogenic risk associated to cervicovaginal cytology were analyzed, in a private laboratory. The results of cytopathologic exams were: within the limits of normality or negative, in 478 cases (57.9\%), ASC-US in 258 cases (31.3\%) and LSIL in 89 cases (10.8\%). As to the mRNA expression of oncoproteins E6/E7 of high-risk HPV, positive results were seen in 203 cases (24.6\%) and absence of expression in 622 (75.4\%). The age level of examined women ranged from 16 to 73 years, with an average of 31.4 years.

The prevalence of mRNA expression of oncoproteins E6/E7 of high oncogenic risk HPV in the three cytological presentation is given in Table 1.

The result of mRNA expression of oncoproteins E6/E7 is associated to cytology ( $<<0.001$ ), in which a higher percentage of positive E6/E7 appears in ASC-US and LSIL cytologies, in a relative comparison with negative cytologies.

There is no statistic difference among ASC-US and LSIL cytologies.

The anatomopathological study on cervix, vagina and/or vulva biopsies in abnormal colposcopic findings was performed in 422 cases, the results of which were described as negative and SIN grade I, relating then with the prevalence of mRNA E6-E7 expression (Table 2).

The result of E6/E7 expression is associated to the anatomopathological result, in which a higher percentage of positive E6/E7 in SIN grau I anatomopathologies was noticed, comparing with the negative anatomopathological exams.

By analyzing the three cytological findings, and relating the mRNA expression of oncoproteins with the biopsy results, an analysis of the agreement with diagnosis methods was searched. There is an agreement between the E6/E7 results and the antomopathological result, for the cases of negative cytology, where the negative expression was related to negative anatomopathology and the positive expression failed to agree with SIN grade I (Table 3). In women with cytopathological exam ASC-US and LSIL, in turn, the mRNA expression of oncoproteins E6/E7 does not agree with the anatomopathological result, i.e., not all the cases with positive expression of E6/E7 bear SIN grade I, as well as not all SIN grade I has expression of E6/E7.

An analysis was conducted for positive cases of mRNA expression of oncoproteins E6/E7, to assess the difference between the presence of the number of HPV genotypes, single or multiple infection and the three cytological forms presented. In five out of the 203 positive cases of E6/E7 mRNA, the genotyping could not be performed for the HPV type, due to technical problems, with only 198 cases being recorded (Table 4).

For positive cases of E6/E7 mRNA expression, the infection by a single HPV type was more prevalent than the infection by multiple types. The type of HPV infection is associated to the LSIL cytologies, comparing 
Table 1. Prevalence of mRNA expression of oncoproteins E6/E7 in high oncogenic risk HPV in patients with negative, ASC-US and LSIL pap exams.

\begin{tabular}{cccc}
\hline & \multicolumn{3}{c}{ E6/E7 mRNA } \\
\hline Cytology & Negative & Positive & Total \\
\hline Negative & $413(86.4 \%)$ & $65(13.6 \%)$ & $478(100.0 \%)$ \\
ASC-US & $158(61.2 \%)$ & $100(38.8 \%)$ & $258(100.0 \%)$ \\
LSIL & $51(57.3 \%)$ & $38(42.7 \%)$ & $89(100.0 \%)$ \\
Total & $622(75.4 \%)$ & $203(24.6 \%)$ & $825(100.0 \%)$ \\
\hline
\end{tabular}

Pearson Qui-square $\mathrm{p}<0.001^{*}$. ASC-US $\times$ LIEBG $\mathrm{p}=0.513$. Legends: ASC-US $=$ atypia of squamous cells of undetermined significance; LSIL $=$ low grade intraepithelial lesion; E6/E7 = mRNA exam for oncoproteins of high oncogenic risk HPV.

Table 2. Prevalence of mRNA expression of oncoproteins E6/E7 of high oncogenic risk HPV in patients with negative and SIN grade 1 anatomopathological exams.

\begin{tabular}{|c|c|c|c|}
\hline \multirow[b]{2}{*}{ Anatomopathological } & \multicolumn{2}{|c|}{ E6/E7 mRNA } & \multirow[b]{2}{*}{ Total } \\
\hline & Negative & Positive & \\
\hline Negative & $241(75.5 \%)$ & $78(24.5 \%)$ & 319 (100.0\%) \\
\hline SIN grade I & $63(61.2 \%)$ & $40(38.8 \%)$ & $103(100.0 \%)$ \\
\hline Total & 304 (72.0\%) & 118 (28.0\%) & 422 (100.0\%) \\
\hline
\end{tabular}

Pearson chi-square $\mathrm{p}=0.005^{*}$. Legend: SIN grade $1=$ squamous intraepithelial neoplasia grade 1 ; E6/E7 = mRNA exam for oncoproteins of high oncogenic risk HPV.

Table 3. Relationship of mRNA expression of oncoproteins E6 and E7 with anatomopathological exam for negative cytologies.

\begin{tabular}{|c|c|c|c|}
\hline \multirow[b]{2}{*}{ Anatomopathological } & \multicolumn{2}{|c|}{ E6/E7 mRNA } & \multirow[b]{2}{*}{ Total } \\
\hline & Negative & Positive & \\
\hline Negative & 175 (79.5\%) & $34(15.5 \%)$ & $209(95.0 \%)$ \\
\hline SIN grau I & $10(4.5 \%)$ & $1(0.5 \%)$ & $11(5.0 \%)$ \\
\hline Total & $185(84.1 \%)$ & 35 (15.9\%) & $220(100.0 \%)$ \\
\hline
\end{tabular}

Noticed agreement $=0.800$. Kappa adjusted by prevalence $=0.600$. Legend: SIN grade $1=$ squamous intraepithelial neoplasia grade 1 ; E6/E7 $=$ mRNA exam for oncoproteins of HPV with high oncogenic risk.

Table 4. Analysis of presence of single or multiple infection in negative, ASC-US and LSIL cytopathological exams, with positive expression of mRNA of oncoproteins E6 and E7.

\begin{tabular}{cccc}
\hline & \multicolumn{3}{c|}{ HPV Genotype } \\
\hline Cytology & Single & Multiple & Total \\
\hline Negative & $57(89.1 \%)$ & $7(10.9 \%)$ & $64(100 \%)$ \\
ASC-US & $87(87.9 \%)$ & $12(12.1 \%)$ & $99(100 \%)$ \\
LSIL & $24(68.6 \%)$ & $11(31.4 \%)$ & $35(100 \%)$ \\
Total & $168(84.8 \%)$ & $30(15.2 \%)$ & $198(100 \%)$
\end{tabular}

Pearson chi-square $=$ multiple infection LSIL $\times$ Negative or ASCUS p $=0,012^{*}$. Legends: ASC-US $=$ atypia of squamous cells-undetermined significance; LSIL = low grade intraepithelial lesion. 
Table 5. HPV genotyping in single infection in negative cytologies, ASC-US and LSIL in cases of positive expression of mRNA of oncoproteins E6/E7.

\begin{tabular}{ccccccc}
\hline & \multicolumn{5}{c}{ HPV Types } \\
\hline Cytology & 16 & 18 & 31 & 33 & 45 & Total \\
\hline Negative & $20(35.1 \%)$ & $9(15.8 \%)$ & $5(8.8 \%)$ & $8(14.0 \%)$ & $15(26.3 \%)$ & $57(100 \%)$ \\
ASC-US & $35(40.2 \%)$ & $9(10.3 \%)$ & $13(15 \%)$ & $19(21.8 \%)$ & $11(12.6 \%)$ & $87(100 \%)$ \\
LSIL & $10(41.6 \%)$ & $2(8.3 \%)$ & $3(12.5 \%)$ & $7(29.2 \%)$ & $2(8.3 \%)$ & $24(100 \%)$ \\
Total & $65(38.7 \%)$ & $20(12.0 \%)$ & $21(12.5 \%)$ & $34(20.2 \%)$ & $28(16.6 \%)$ & $168(100 \%)$ \\
\hline
\end{tabular}

Statistic Test: Pearson Chi-square $\mathrm{p}=0.289$. Legends: ASC-US $=$ atypia of squamous cells of undetermined significance; LSIL $=$ low grade intraepithelial lesion.

with the negative and ASC-US cytologies. Also, there is a higher percentage of single infection in negative and ASC-US cytologies, comparing with the LSIL cytologies.

The HPV genotyping was analyzed in positive cases E6/E7 mRNA expression, for the infection type by a single agent.

The HPV types 16, 18, 31, 33 and 45 were equally frequent in the three cytologies analyzed, with a higher frequency of HPV 16 being noticed, followed by 33, mainly in altered cytologies, but with no statistical significance (Table 5).

\section{Discussion}

The value of the mRNA study using the Pretect HPV-Proofer technology was analyzed by Rijkaart et al., 2012, in a prospective screening study, where women with high oncogenic risk were stratified and sent for colposcopic study. As a result, risk of CIN2+ was found in 55\% of DNA women with high oncogenic risk, positive and normal oncotic cytologies, and with E6/E7 mRNA expression, comparing to the 20\% risk in those with negative mRNA. It was concluded that this test can be used for women with high oncogenic risk, for the prediction of CIN 2+ risk, thus avoiding unnecessary follow-up and costs [16].

With this rationale, which delineates the higher risk of women with positive mRNA expression, this study was conducted with the intention of assessing the prevalence of mRNA expression in a population with current or former history of HPV infection, where 825 women were assessed. The negative cytology finding was noticed in 478 cases, ASCUS cytology in 258 cases and LSIL in 89 patients. A the E6/E7 mRNA expression was found in $24.6 \%$ of the total, with $13.6 \%$ of positivity in women with negative cytologies, $38.8 \%$ in those with ASC-US cytologies and $42.7 \%$ in those with LSIL, a prevalence a little higher than in the study by Castro et al., 2013; in a prospective analysis, positive E6/E6 mRNA expression was found in 37.8\% of patients with negative cytology, $55.7 \%$ in patients with ASC-US cytology and LSIL and 77.5\% of positive expression for high grade (HSIL) cytologies. Nearly $26 \%$ of women with ASC-US or LSIL cytologies had moderate/severe cervical intraepithelial neoplasia, in the follow-up [17].

Since this was a retrospective research, without the follow-up of said women, and based on official papers findings, it is noticed that said prevalence of positivity in ASCUS and LSIL cytologies are stratified with risk patients, and deserve more surveillance. Women whose biopsy would indicate high grade neoplasy were excluded, with only the cases whose biopsies were negative or presenting low grade neoplasia were being analyzed. Despite the exclusion of high grade lesions, which would act as a conclusion for such a type of assessment, a significant association among ASC-US and LSIL cytologies was noticed, and positive expression of E6/E7 mRNA expression, comparing with negative cytologies. This demonstrates that the cellular alterations, even though in minimum level, are already liable the oncogenic activity of the virus, identifying the cases deserving more surveillance. A high grade lesion is a fact for prompt conduct, with minor cytologies, in turn, being doubtful as to the conduction; the mRNA expression can be an alert for investigation.

It is suggested that the revaluation interval could be shorter, only by the cytological alteration with positive expression. Official papers include citations that this would be the ideal tracking method, according to Castro, due to the high sensibility and specificity for detection of moderate/severe cervical intraepithelial neoplasia [17].

No sensibility or specificity were assessed, as well as no diagnosis methods were proposed, since they were 
not among the objectives.

Almost $40 \%$ of positive expression of E6/E7 mRNA were found in patients with SIN grade 1\% and 24.5\% with negative anatomopathological findings. The study by Anderson et al., 2006, found 50\% of expression in patients with CIN $1 \%$ and $14 \%$ with negative hystology. While they are studies delineated in different forms, one might infer that said women present a higher potential for the development of high grade lesions than in cases the expression is negative for E6/E7 [18].

When the type of infection was analyzed in respect to the number of involved HPV, in positive cases of oncoproteins expression, a higher prevalence was seen for infections by a single HPV type, in special in negative and ASCUS cytologies, comparing with LSIL. A higher prevalence of multiple types in LSIL was noticed, with $31.4 \%, 12.1 \%$ in those with ASC-US cytologies and $10.9 \%$ in those with negative cytologies; said findings agree with the study by Brismar-Wendel et al., 2009, where a higher percentage of multiple infections was noticed in patients with LSIL than those with ASC-US. Another study, as that of Spinillo et al., 2009, found however a significant increase of high grade CIN in patients with infections by multiple types of HPV, comparing with patients with single infections. They also verified that younger patients had more infections by multiple viral types. Said paper goes against our findings, whose positive expression was more prevalent by a single HPV type, in view of which a higher evolutive risk is featured [19] [20].

Correnti et al., 2011, also found a higher percentage of multiple infections in patients with low grade infections, comparing with patients with cervix carcinoma, said findings also agreeing with the studies by Gargiulo et al., 2007 and Carozzi et al., 2010 [21]-[23].

This research also found that HPV 16 is the most common type in patients with single infection with positive expression of E6/E7 mRNA, although no significance in respect to other types or among different cytological findings having been shown. Official papers demonstrate that type 16 is the most prevalent among the viral types in patients infected by HPV [19] [21]. Several studies demonstrated that HPV 16 is the most common viral type in low- and high grade infections. Types 16 and 18 are related to a higher probability of progression to malignity, even in patients with minor cytological alterations (ASC-US and LSIL) which present these high oncogenic risk HPV [6] [9] [21].

HPV 33 was the second most common type in ASC-US and LSIL cytologies, and type 45 in negative cytologies; Sorbye et al., 2011, and Keegan et al., 2009, also found the type 33 as the second most prevalent type. No great prevalence of HPV 18 was seen in the three cytologies. It is known that this type of HPV is more related to glandular alterations and adenocarcinoma, which are of difficult diagnosis based only in oncotic cytology, and no alterations to glandular cells was analysed in this research [24] [25].

With our study, through the high prevalence of mRNA expression in less significant cytological alterations, the evolution of which was not a high grade, one can suggest that patients can be stratified as high risk for progression; they deserve a strict follow-up as to a possible evolution for preceding lesions. The persistence and integration of high-risk virus are factors of risk for the development of cervix cancer, said fact being already identified in several official papers.

\section{Conclusions}

The obtained results allow to conclude that:

- The mRNA expression of oncoproteins E6/E7 of high oncogenic risk HPV was more prevalent in ASC-US and LSIL cytologies, comparing with negative cytologies.

- The anatomopathological finding for SIN grade I was related to the positive expression of mRNA of oncoproteins E6/E7. When this finding was specified for each type of pap exam, the negative expression of mRNA agreed with the negative anatomopathological finding of negative cytology, with no ASC-US and LSIL occurring in the exams.

Infection by a type of HPV was more frequent in cases of positive mRNA expression of oncoproteins E6/E7. A higher percentage of multiple infections occurred in LSIL cytologies. On the other hand, a higher number was evidenced in single infection, in special by HPV type 16 in negative pap exams and ASC-US, followed by type 33 in all the pap variants being studied.

\section{References}

[1] World Health Organization (2009) World Health Statistic. 
http://www.who.int/gho/publications/world_health_statistics/EN_WHS09_Full.pdf?ua=1

[2] INCA. Instituto Nacional do Câncer (2014) Ministério da Saúde. Estimativa 2014: Incidência de câncer no Brasil. Rio de Janeiro.

[3] Stanley, M. (2010) Pathology and Epidemiology of HPV Infection in Females. Gynecologic Oncology, 117, S5-S10. http://dx.doi.org/10.1016/j.ygyno.2010.01.024

[4] Kjaer, S.K., den Brule, J.C., Paull, G., Svare, E.I., Sherman, M.E., Thomsen, H.L., et al. (2002) Type Specific Persistence of High Risk Human Papillomavirus (HPV) as Indicator of High Grade Cervical Squamous Intraepithelial Lesions in Young Women: Population Based Prospective Follow up Study. British Medical Journal, 325, 1-7. http://dx.doi.org/10.1136/bmj.325.7364.572

[5] Panatto, D., Amicizia, D., Trucchi, C., Casabona, F., Lai, P.L., Bonanni, P., et al. (2012) Sexual Behavior and Risk Factors for the Acquisition of Human Papillomavirus Infections in Young People in Italy: Suggestions for Future Vaccination Policies. BMC Public Health, 12, 623. http://dx.doi.org/10.1186/1471-2458-12-623

[6] Bosch, F.X. and de Sanjosé, S. (2007) The Epidemiology of Human Papillomavirus Infection and Cervical Cancer. Disease Markers, 23, 213-227. http://dx.doi.org/10.1155/2007/914823

[7] Bouvard, V., Baan, R., Straif, K., Grosse, Y., Secretan, B., El Ghissassi, F., et al. (2009) A Review of Humans Carcinogens-Part B: Biological Agents. The Lancet Oncology, 10, 321-322. http://dx.doi.org/10.1016/S1470-2045(09)70096-8

[8] Castellsagué, X. (2008) Natural History and Epidemiology of HPV Infection and Cervical Cancer. Gynecologic Oncology, 110, S4-S7. http://dx.doi.org/10.1016/j.ygyno.2008.07.045

[9] Muñoz, N., Bosch, F.X., de Sanjose, S., et al. (2003) Epidemiologic Classification of Human Papillomavirus Types Associated with Cervical Cancer. The New England Journal of Medicine, 348, 518-527. http://dx.doi.org/10.1056/NEJMoa021641

[10] Moody, C.A. and Laimins, L.A. (2010) Human Papillomavirus Oncoproteins: Pathways to Transformation. Nature Reviews Cancer, 10, 550-560. http://dx.doi.org/10.1038/nrc2886

[11] Martin, C.M. and O’Leary, J.J. (2011) Histology of Cervical Intraepithelial Neoplasia and the Role of Biomarkers. Best Practice \& Research Clinical Obstetrics and Gynecology, 25, 605-615. http://dx.doi.org/10.1016/j.bpobgyn.2011.04.005

[12] Brown, A.J. and Trimble, C.L. (2012) New Technologies for Cervical Cancer Screening. Best Practice \& Research Obstetrics and Gynaecology, 26, 233-242. http://dx.doi.org/10.1016/j.bpobgyn.2011.11.001

[13] Tornesello, M.L., Buonaguro, L., Giorgi-Rossi, P. and Buonaguro, F.M. (2013) Viral and Cellular Biomarkers in the Diagnosis of Cervical Intraepithelial Neoplasia and Cancer. BioMed Research International, 1-10.

[14] Molden, T., Kraus, I., Karlsen, F., Skomedal, H. and Hagmar, B. (2006) Human Papillomavirus E6/E7 mRNA Expression in Women Younger than 30 Years of Age. Gynecologic Oncology, 100, 95-100. http://dx.doi.org/10.1016/j.ygyno.2005.07.108

[15] Jeantet, D., Schwarzmann, F., Tromp, J., Melchers, W.J.G., van der Wurff, A., Oosterlaken, T., et al. (2009) NucliSENS ${ }^{\circledR}$ EasyQ ${ }^{\circledR}$ HPV v1 Test-Testing for Oncogenic Activity of Human Papillomaviruses. Journal of Clinical Virology, 45, S29-S37. http://dx.doi.org/10.1016/S1386-6532(09)70006-X

[16] Rijkaart, D.C., Heildeman, D.A.M., Cupe, V.M.H., Brink, A.A.T.P., Verheijen, R.H.M., Skomedal, H., et al. (2012) High-Risk Human Papillomavirus (hrHPV) E6/ E7 mRNA Testing by PreTect HPV-Proofer for Detection of Cervical High-Grade Intraepithelial Neoplasia and Cervical among hrHPV DNA-Positive Women with Normal Cytology. Journal of Clinical Microbiology, 50, 2390-2396. http://dx.doi.org/10.1128/JCM.06587-11

[17] Castro, S.P., Fernández, A.I., González, M.J., Sarán Diez, M.T., Lama, A.C., Martín, M.J.A., et al. (2013) Human Papillomavirus (HPV) E6/E7 mRNA as a Triage Test after Detection of HPV 16 and HPV 18 DNA. Journal of Medical Virology, 85, 1063-1068. http://dx.doi.org/10.1002/jmv.23544

[18] Andersson, S., Hansson, B., Norman, I., Gaberi, V., Mints, M., Hjerpe, A., et al. (2006) Expression of E6/E7 mRNA from “High Risk" Human Papillomavirus in Relation to CIN Grade, Viral Load and p16 $6^{\text {INK4a }}$. International Journal of Oncology, 29, 705-711.

[19] Brismar-Wendel, S., Froberg, M., Hjerpe, A., Anderson, S. and Johansson, B. (2009) Age-Specific Prevalence of HPV Genotypes in Cervical Cytology Samples with Equivocal or Low-Grade Lesions. British Journal of Cancer, 101, 511517. http://dx.doi.org/10.1038/sj.bjc.6605165

[20] Spinillo, A., Dal Bello, B., Garddella, B., Roccio, M., Dacco, M.D. and Silini, E.M. (2009) Multiple Human Papillomavirus Infection and High Grade Cervical Intraepithelial Neoplasia among Women with Cytological Diagnosis of Atypical Squamous Cells of Undetermined Significance or Low Grade Squamous Intraepithelial Lesions. Gynecologic Oncology, 113, 115-119. http://dx.doi.org/10.1016/i.ygyno.2008.12.037 
[21] Correnti, M., Medina, F., Cavazza, M.E., Rennola, A., Ávila, M. and Fernándes, A. (2011) Human Papillomavirus (HPV) Type Distribution in Cervical Carcinoma, Low-Grade, and High-Grade Squamous Intraepithelial Lesions in Venezuelan Women. Gynecologic Oncology, 121, 527-531. http://dx.doi.org/10.1016/j.ygyno.2011.02.003

[22] Gargiulo, F., De Francesco, M.A., Schreiber, C., Ciravolo, G., Salinaro, F., Valloncini, B., et al. (2007) Prevalence and Distribution of Single and Multiple HPV Infections in Cytologically Abnormal Cervical Samples from Italian Women. Virus Research, 125, 176-182. http://dx.doi.org/10.1016/j.virusres.2006.12.017

[23] Carozzi, F.M., Tornesello, M.L., Burroni, E., Loquercio, G., Carillo, G., Angeloni, C., et al. (2010) Prevalence of Human Papillomavirus Types in High-Grade Cervical Intraepithelial Neoplasia and Cancer in Italy. Cancer Epidemiology, Biomarkers \& Prevention, 19, 2389-2400. http://dx.doi.org/10.1158/1055-9965.EPI-10-0131

[24] Sorbye, S.W., Arbyn, M., Fismen, S., Gutteberg, T.J. and Mortesen, E.S. (2011) Triage of Women with Low-Grade Cervical Lesions-HPV mRNA Testing versus Repeat Cytology. PLoS ONE, 6, e24083. http://dx.doi.org/10.1371/journal.pone.0024083

[25] Keegan, H., Inerney, J.M., Pilkington, L., Gronn, P., Silva, I., Karlsen, F., et al. (2009) Comparation of HPV Detection Technologies: Hybrid Capture 2, PreTect HPV-Proffer and Analysis of HPV DNA Viral in HPV 16, HPV 18 and HVP 33 E6/E7 mRNA Positive Specimens. Journal of Virological Methods, 155, 61-66. http://dx.doi.org/10.1016/j.jviromet.2008.09.027 
Scientific Research Publishing (SCIRP) is one of the largest Open Access journal publishers. It is currently publishing more than 200 open access, online, peer-reviewed journals covering a wide range of academic disciplines. SCIRP serves the worldwide academic communities and contributes to the progress and application of science with its publication.

Other selected journals from SCIRP are listed as below. Submit your manuscript to us via either submit@scirp.org or Online Submission Portal.
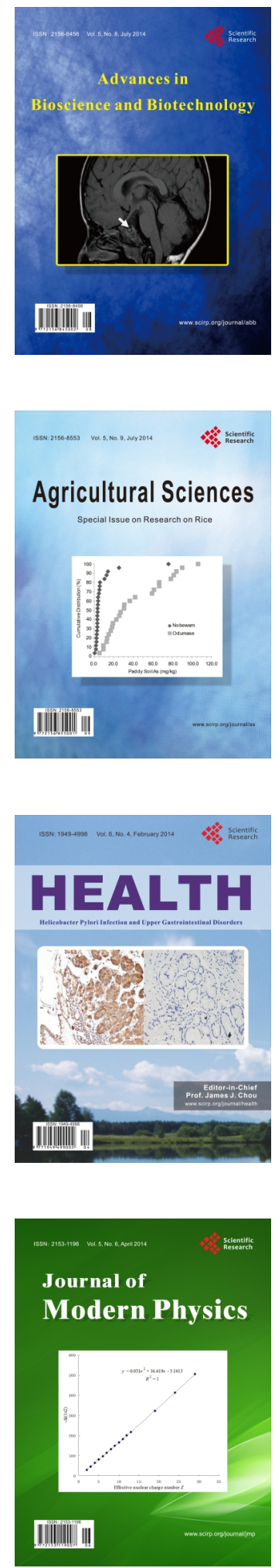
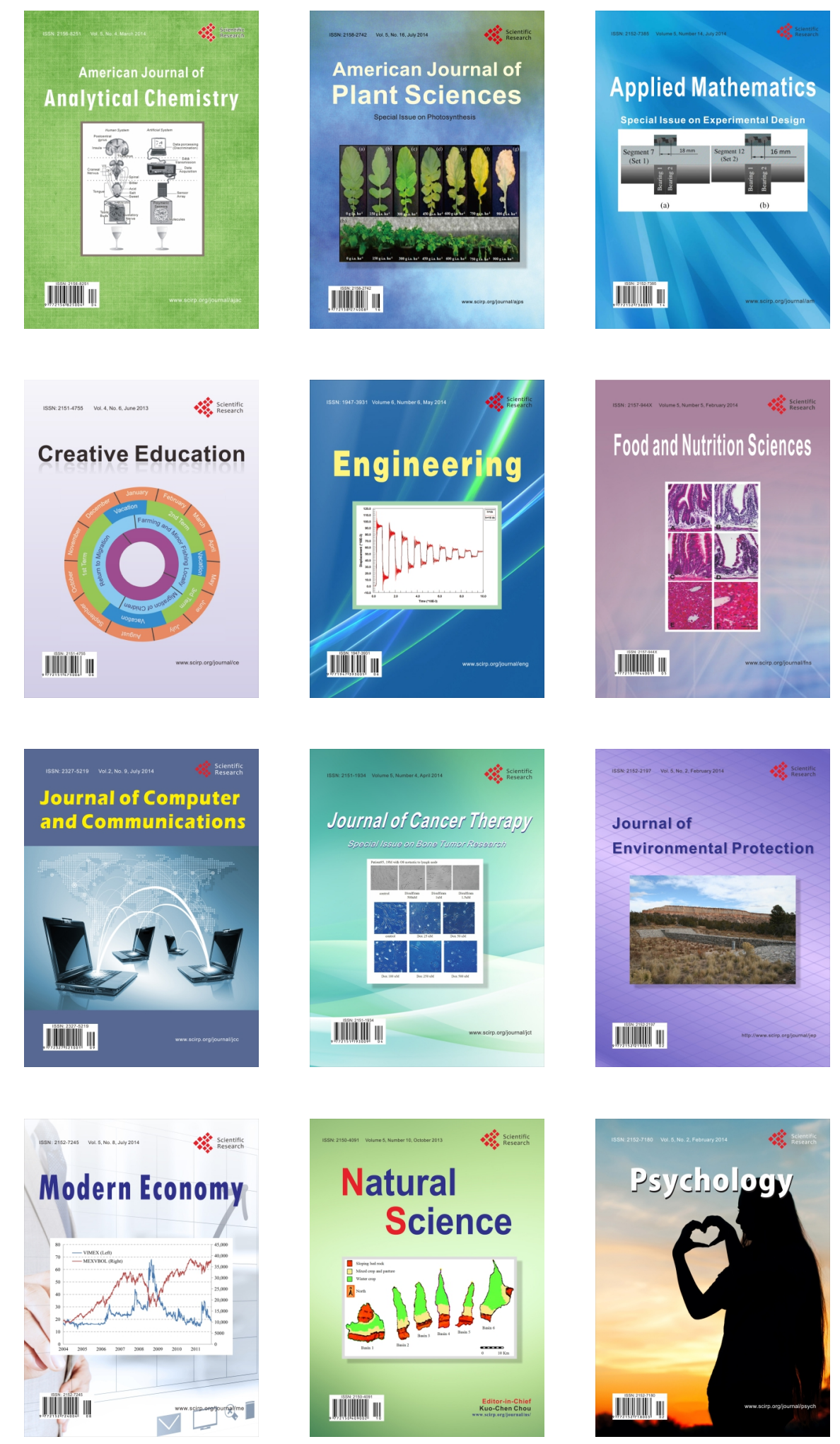